\title{
Complications of NewColorlris implantation in phakic eyes: a review
}

This article was published in the following Dove Press journal:

Clinical Ophthalmology

4 April 201 I

Number of times this article has been viewed

\author{
Shameema Sikder' \\ Scott W Davis ${ }^{2}$ \\ Huck Holz ${ }^{3}$ \\ Majid Moshirfar ${ }^{4}$ \\ 'The Wilmer Eye Institute, Johns \\ Hopkins University, Baltimore, \\ MD, USA; ${ }^{2}$ Drexel University College \\ of Medicine, Philadelphia, PA, USA; \\ ${ }^{3}$ Kaiser Permanente Medical Group, \\ Santa Clara, CA, USA; ${ }^{4}$ The John A \\ Moran Eye Center, Salt Lake City, \\ UT, USA
}

Purpose: To provide a literature review of implant related complications from bilateral NewColorIris implantation (Kahn Medical Devices, Panama City, Panama).

Methods: A PubMed search of peer-reviewed ophthalmology journals for complications related to NewColorIris implants was performed.

Results: Including a recent case published by the authors, a total of nine patients (18 eyes) with management of complications such as endothelial cell loss, elevated intraocular pressure (IOP), corneal edema, anterior chamber inflammation, decreased visual acuity, and cataract formation were reviewed.

Conclusions: Sight-threatening complications including corneal decompensation, IOP elevation, uveitis, and hyphema have been described after NewColorIris implantation.

Keywords: intraocular pressure, footplates, elevated IOP

\section{Introduction}

For the purposes of cosmetic eye color change, NewColorIris (Kahn Medical Devices, Panama City, Panama) silicone prosthesis implants were developed in 2004. ${ }^{1}$ Although not approved by the Food and Drug Administration (FDA), implantation has been performed with subsequent complications noted in the literature, including endothelial cell loss, elevated intraocular pressure (IOP), corneal edema, anterior chamber inflammation, decreased visual acuity, and cataract formation. ${ }^{2-8}$ While not specific to the NewColorIris, placement of phakic intraocular lenses have been associated with posterior segment complications, such as giant retinal tears. ${ }^{9}$

In recent years, NewColorIris implants have been removed following the development of acute and chronic side effects. ${ }^{2-4,6-8,10}$ This paper summarizes the published cases of complications arising from NewColorIris implantation for cosmesis in phakic eyes.

\section{Results}

Table 1 was compiled from a PubMed search of peer-reviewed ophthalmology journals. To our knowledge, only eight cases (16 eyes) with complications following NewColorIris cosmetic implantation surgery had been published prior to the submission of our recent case..$^{2-9}$ Of the nine known cases (18 eyes) including our own, six of the nine $(66.7 \%)$ involve female patients. The only available long-term safety data comes from the manufacturer, which studied twelve female patients ( 24 eyes) with a mean endothelial cell density loss of $2.6 \%$ after eight months of follow-up. ${ }^{1}$ In this series,
Correspondence: Majid Moshirfar The John A Moran Eye Center, 65 Mario Capecchi Drive, Salt Lake City, UT 84I32, USA

Tel + I 80I 5873020

Fax + I 80I 58I 3357

Email majid.moshirfar@hsc.utah.edu 
Table I Cases of NewColorlris implantation for cosmesis

\begin{tabular}{|c|c|c|c|c|c|c|c|c|}
\hline Source & $\begin{array}{l}\text { Age/sex/ } \\
\text { implant } \\
\text { color }\end{array}$ & $\begin{array}{l}\text { Time to } \\
\text { symptom } \\
\text { onset }\end{array}$ & Eye & $\begin{array}{l}\text { Time to } \\
\text { explantation }\end{array}$ & $\begin{array}{l}\text { BCVA } \\
\text { pre/post } \\
\text { explantation }\end{array}$ & $\begin{array}{l}\text { IOP }(\mathrm{mmHg}) \\
\text { at presentation/ } \\
\text { peak/last } \\
\text { follow-up }\end{array}$ & $\begin{array}{l}\text { Endothelial } \\
\text { cell density } \\
\left(\text { cells } / \mathrm{mm}^{2}\right)\end{array}$ & $\begin{array}{l}\text { Presence } \\
\text { of corneal } \\
\text { edema/ } \\
\text { hyphema }\end{array}$ \\
\hline \multirow{4}{*}{$\begin{array}{l}\text { Anderson } \\
\text { et } \mathrm{al}^{2}\end{array}$} & 27/F/green & 2 weeks & OD & $\sim 3$ weeks & $\mathrm{HM} / 20 / 60$ & $44 / 44 / 12$ & 206 & $+/+$ \\
\hline & & & OS & $>I$ month & $20 / 20 / 20 / 20$ & $11 / 19 / 19$ & 1292 & NM/NM \\
\hline & 40/F/green* & 4 weeks & OD & - & $20 / 20 / \mathrm{CF}$ & $24 / 24 / 13$ & 662 & $+/ \mathrm{NM}$ \\
\hline & & & OS & - & $20 / 25 / 20 / 40$ & $14 / 14 / 8$ & 1137 & $+/ \mathrm{NM}$ \\
\hline \multirow{2}{*}{$\begin{array}{l}\text { Arthur } \\
\text { et } \mathrm{al}^{3}\end{array}$} & 29/M/green** & 6 months & OD & $\sim 13$ months & $20 / 30 / 20 / 30$ & $38 / 38 / 15$ & 837 & $+/+$ \\
\hline & & & OS & $\sim 13$ months & $20 / 70 / 20 / 150$ & $40 / 40 / 10$ & 1083 & $+/+$ \\
\hline \multirow[t]{2}{*}{$\begin{array}{l}\text { Castanera } \\
\text { et } \mathrm{al}^{4}\end{array}$} & 30/F/blue & I week & OD & $\begin{array}{l}\text { Not clear if } \\
\text { explanted }\end{array}$ & $20 / 160 / 20 / 125$ & $36 / 36 / 16$ & $N / A$ & $+/ N M$ \\
\hline & & & OS & - I week & $\mathrm{CF} / 20 / 50$ & $39 / 39 / 16$ & $N / A$ & $+/ \mathrm{NM}$ \\
\hline \multirow{2}{*}{$\begin{array}{l}\text { Hull } \\
\text { et al }\end{array}$} & 27/F/blue & 2 weeks & OD & 2-3 weeks & $20 / 100 / 20 / 20$ & I6/36/wnl & 2476 & $+/ \mathrm{NM}$ \\
\hline & & & OS & 2-3 weeks & $20 / 40 / 20 / 16$ & $32 / 42 / \mathrm{wnl}$ & 2089 & $+/ \mathrm{NM}$ \\
\hline \multirow[t]{2}{*}{ Macdonald ${ }^{7}$} & $60 / F /-$ & 6 months & OD & - & - & - & - & $+/ \mathrm{NM}$ \\
\hline & & & OS & - & - & - & - & $+/ \mathrm{NM}$ \\
\hline \multirow[t]{2}{*}{ Thiagalingam $^{8}$} & 19/M/blue & 13 days & OD & 5 weeks & $20 / 40 / 20 / 20$ & $19 / 50 / 17$ & 1149 & $+/ \mathrm{NM}$ \\
\hline & & & OS & 6 weeks & $20 / 40^{+2} / 20 / 20$ & $19 / 40 / 17$ & 1353 & $+/ N M$ \\
\hline \multirow{2}{*}{$\begin{array}{l}\text { Garcia-Pous } \\
\text { et al }\end{array}$} & $21 / F / g r e e n$ & 3 weeks & OD & - & $20 / 60 /-$ & 30/30/“controlled” & $107 \mid$ & NM/NM \\
\hline & & & OS & - & 20/80/- & 35/35/“controlled” & 950 & $\mathrm{NM} / \mathrm{NM}$ \\
\hline \multirow[t]{2}{*}{$\begin{array}{l}\text { Sikder } \\
\text { et al }\end{array}$} & 19/M/blue & I week & OD & $4-5$ months & $20 / 20 / 20 / 25$ & $14 / 16 / 12$ & - & $\begin{array}{l}\text { Absent/ } \\
\text { absent }\end{array}$ \\
\hline & & & OS & $4-5$ months & $20 / 20 / 2 / 25^{+2}$ & $14 / 14 / 15$ & - & $\begin{array}{l}\text { Absent/ } \\
\text { absent }\end{array}$ \\
\hline
\end{tabular}

Notes: *Underwent LASIK OU 4 months prior to implants; **Patient became symptomatic after sustaining airbag trauma in a motor vehicle accident six months after surgery.

Abbreviations: BCVA, best corrected visual acuity; CF, counting fingers; HM, hand motion; IOP, intraocular pressure; NM, no mention of the corresponding exam finding; OD, right eye; OS, left eye; OU, both eyes.

only one patient (two eyes) required explantation due to uveitis and ocular hypertension. Our review summarizes nine cases (18 eyes), including one new bilateral case encountered by us that together suggest a need for more information regarding the long-term safety of NewColorIris implantation.

Symptomatic patients can be stratified into early ( $<1$ month) or late ( $>6$ months) symptom onset, with seven of nine cases $(77.8 \%)$ presenting in the first postoperative month. Several of these patients reported immediate complications including hyphema, elevated intraocular pressure, and blurred vision. ${ }^{2,6}$ Others were asymptomatic in the immediate postoperative period, but developed complaints in the following weeks. ${ }^{4,5,8}$ The most common complaint amongst early and late presenters was decreased visual acuity/blurred vision, which was present in all nine patients (18 eyes, 100\%). At last follow-up, nine of the 16 eyes $(56.25 \%)$ had decreased best corrected visual acuity (BCVA), which is the same number of eyes with sub-optimal BCVA at presentation (Table 1).

In the early presentation cohort, only one of 14 eyes (7.1\%) displayed hyphema, which resolved after anterior chamber paracentesis and two $25 \mathrm{mcg}$ tissue plasminogen activator (tPA) injections. ${ }^{2}$ A proportionately higher two of four eyes $(50 \%)$ in the late presentation group developed hyphema, which resolved with conservative pharmacological management. ${ }^{3}$ Corneal edema and elevated intraocular pressure were more common findings, occurring in 13 of 16 eyes (81.25\%) and 12 of 16 eyes $(75 \%)$, respectively (Table 1). Exam findings were not available for one patient. ${ }^{7}$ All published cases indicate anterior chamber inflammation visible by slit-lamp exam.

Several patients required surgery in addition to explantation. These procedures included: three trabeculectomies for IOP management, two Descemet Stripping Automated 
Endothelial Keratoplasties (DSAEK), and three peripheral iridotomies, two of which were performed by the implant surgeon. ${ }^{2,3,6,7}$ Hull et al, in their case report of a 27-year-old female who presented with a large peripheral iridotomy, contended that their patient's account of acute pain upon implantation suggests that the iridotomy was performed intraoperatively in response to iris-prolapse. ${ }^{6}$ Aside from the aforementioned procedures, one other patient was undergoing evaluation for Descemet's stripping endothelial keratoplasty (DSEK) secondary to ongoing corneal edema at last follow-up. ${ }^{2}$

\section{Discussion}

In order to better understand the pathogenesis of the numerous complications seen in NewColorIris-implanted eyes, it is helpful to consider reported irregularities in the implants themselves. Several case reports in the literature identify manufacturing defects that likely contribute to implant dysfunction. In one such study, scanning electron microscope (SEM) images revealed surface irregularities and sharp edges that may contribute to the abrasion of the corneal endothelium and iris. ${ }^{4}$ Concerns about the implant's peripheral footplates have also been documented. According to the manufacturer, these footplates are responsible for minimizing the implant's interaction with the trabecular meshwork. ${ }^{11}$ However, Anderson et al report that four of six footplates were missing from one of the explanted prostheses in their case report. They suspect that part of the implant had been hand-cut, resulting in significant edge irregularity. ${ }^{2}$ Several authors have also demonstrated a tendency of the NewColorIris implant to directly contact the angle structures. ${ }^{3,4,8}$ Pentacam images of our patient similarly illustrate the implant's close proximity to the iris and angle (Figure 1). These prostheses not only impinge on the angle structures, but shift position with time. Our patient displayed a temporally-shifted implant (Figure 2), while another case in the literature describes a nasally-decentered presentation. Other authors have published images demonstrating improperly-sized implants that exhibit vaulting within the anterior chamber. ${ }^{2}$

The pathogenesis of the IOP increases commonly seen in these patients may be multifactorial. In light of microscopic images showing pigment-laden macrophages and direct pigment deposition on the surface of the implant, some authors have attributed the rise to iris pigment liberation. ${ }^{2,6,8}$ Others have cited the implant's direct contact with angle structures..$^{2-4,6,8}$ Explantation is an effective means of
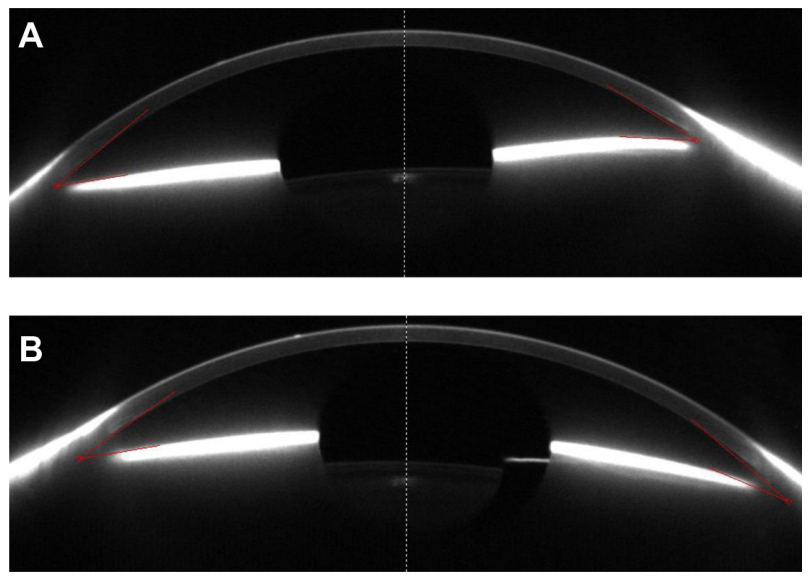

Figure I Pentacam image showing a silicone NewColorlris implant in the anterior chamber in the (A) right eye, with close apposition with the angle and (B) left eye, with asymmetry within the anterior chamber relative to the angle.

controlling elevated IOP, but some patients may require long-term postoperative pharmacotherapy. ${ }^{2}$

In some cases, explanted eyes suffered insults that may lead to future complications. Our patient, like the one presented by Thiagalingam et al, developed bilateral premature sclerotic changes in his native lenses. ${ }^{8}$ A 30-year-old female described by Castanera et al experienced visual field deficits in her follow-up period. ${ }^{4}$ Other eyes were found to have significant corneal decompensation..$^{2,3,5,8}$ Due to the high likelihood of postexplantation sequelae in these patients, they should receive long-term follow up with IOP, BCVA, endothelial cell counts, specular microscopy, and gonioscopy.

Steps should be taken to select appropriate candidates for artificial iris implantation. Currently, no criteria for candidacy have been established. While anterior chamber depth and baseline endothelial cell density should be evaluated, close attention must be given to the dimensions of the cornea at the limbus. Given the asymmetry of the horizontal and vertical meridians of the cornea, the anterior chamber would not uniformly support a perfectly circular implant. Furthermore, a detailed and careful evaluation of

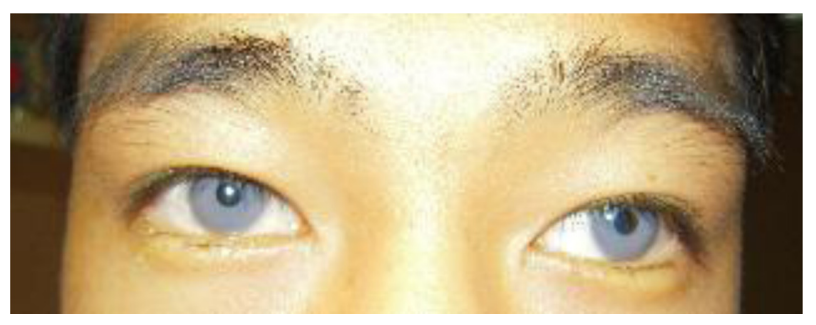

Figure 2 Patient with blue NewColorlris implants OU. Note the temporal displacement of the left implant with a decentered light reflex. 
the iris must be performed. The eccentricity of the pupillary aperture should be assessed. Evaluation of the configuration of the iris root by imaging modalities could reveal variants such as plateau configuration, which would increase the risk of iris chafing. Specific measurement of each individual patient's anatomy may permit custom sizing of the implant in the future, with decreased associated risk of complications. Nevertheless, if preoperative evaluation suggests a patient may be a good candidate for an elective NewColorIris implant, this procedure currently has no proven safety record and may result in urgent explantation and long-term sightthreatening sequelae.

Although it is difficult to estimate the extent of complications as it is unknown how many NewColorIris implants have been implanted, review of the literature reveals visionthreatening complications such as elevated IOP, intraocular inflammation, and corneal decompensation. With its current design, implantation should be seriously deliberated and risks such as possible surgery for cataracts, elevated IOP, and explantation should be extensively discussed with potential patients.

\section{Acknowledgment}

This project was supported by the Research to Prevent Blindness foundation, New York, NY, USA.

\section{Disclosure}

No conflicts of interest were declared in relation to this paper.

\section{References}

1. Kahn DA, Liakopulos P. New cosmetic artificial iris diaphragm implant (Newiris): 8 months follow-up. Presented at the Joint Meeting of the American Academy of Ophthalmology and the European Society of Ophthalmology. October 2004.

2. Anderson JE, Grippo TM, Sbeity Z, Ritch R. Serious complications of cosmetic NewColorIris implantation. Acta Ophthalmol. 2010;88(6): 700-704.

3. Arthur SN, Wright MM, Kramarevsky N, Kaufman SC, Grajewski AL. Uveitis-glaucoma-hyphema syndrome and corneal decompensation in association with cosmetic iris implants. Am J Ophthalmol. 2009; 148(5):790-793.

4. Castanera F, Fuentes-Páez G, Ten P, Pinalla B, Guevara O. Scanning electron microscopy of explanted cosmetic iris implants. Clin Experiment Ophthalmol. 2010;38(6):648-651.

5. Garcia-Pous M, Udaondo P, Garcia-Delpech A, et al. Acute endothelial failure after artificial iris-lens diaphragm implantation (NewIris) for cosmetic purposes. American Academy of Ophthalmology. Poster presentation. 2006.

6. Hull S, Jayaram H, Mearza AA. Complications and management of cosmetic anterior chamber iris implants. Cont Lens Anterior Eye. 2010; 33(5):235-238.

7. MacDonald L. Cosmetic iris implants - is vanity worth losing your vision? Optometry J Am Optometric Assoc. 2010;81(6):281-282.

8. Thiagalingam S, Tarongoy P, Hamrah P, et al. Complications of cosmetic iris implants. J Cataract Refract Surg. 2008;34(7):1222-1224.

9. Georgalas I, Petrou P, Papaconstantinou D, Koutsandrea C, Ladas I. Bilateral giant tear-associated retinal detachment following Artisan phakic intraocular lens implantation for correction of moderate myopia. Acta Ophthalmol. 2010;88(4):e143-e144.

10. Sikder S, Davis SW, Patel VP, Holz H, Moshirfar M. Complications and management of NewColorIris implantation in phakic eyes. $J$ Refract Surg. 2011. In press.

11. Groves N, Kahn DA. Diaphragm implant safely changes color of iris. Ophthalmol Times. 2005 Apr 15:72.
Clinical Ophthalmology

\section{Publish your work in this journal}

Clinical Ophthalmology is an international, peer-reviewed journal covering all subspecialties within ophthalmology. Key topics include: Optometry; Visual science; Pharmacology and drug therapy in eye diseases; Basic Sciences; Primary and Secondary eye care; Patient Safety and Quality of Care Improvements. This journal is indexed on Submit your manuscript here: http://www.dovepress.com/clinical-ophthalmology-journal

\section{Dovepress}

PubMed Central and CAS, and is the official journal of The Society of Clinical Ophthalmology (SCO). The manuscript management system is completely online and includes a very quick and fair peer-review system, which is all easy to use. Visit http://www.dovepress.com/ testimonials.php to read real quotes from published authors. 